\title{
Predictive factors for perinatal death in nuchal cord cases: a case control study
}

\section{Pascal Foumane $^{1 *}$, Séraphin Nguefack ${ }^{2}$, Jeanne Hortense Fouedjio ${ }^{1}$, Aurélie Bitnkeu Assam ${ }^{1}$, Julius Sama Dohbit ${ }^{1}$, Emile Telesphore Mboudou ${ }^{1}$}

\author{
${ }^{1}$ Department of Obstetrics and Gynecology, Faculty of Medicine and Biomedical Sciences (FMBS), The University of \\ Yaoundé, Cameroon \\ ${ }^{2}$ Department of Pediatrics, Faculty of Medicine and Biomedical Sciences (FMBS), The University of Yaoundé 1, \\ Cameroon
}

Received: 04 October 2016

Accepted: 02 November 2016

\section{*Correspondence:}

Dr. Pascal Foumane,

E-mail: pfoumane2004@yahoo.fr

Copyright: (C) the author(s), publisher and licensee Medip Academy. This is an open-access article distributed under the terms of the Creative Commons Attribution Non-Commercial License, which permits unrestricted non-commercial use, distribution, and reproduction in any medium, provided the original work is properly cited.

\section{ABSTRACT}

Background: Nuchal cord is a common occurrence at delivery and it is known to be associated with birth asphyxia and perinatal death. The objective of this study was to identify the predictive factors of perinatal death in the presence of nuchal cord.

Methods: This was a case-control study carried out during the period from October 1st 2014 to April 30 th 2015 in three hospitals of Yaoundé, Cameroon, involving 204 parturients whose babies presented with a nuchal cord at delivery.

Results: After multivariate analysis, independent predictive factors for perinatal death in nuchal cord cases were: post-term $(\mathrm{OR}=209.70 ; \mathrm{CI}=3.09$-14212.66), antepartum hemorrhage $(\mathrm{OR}=18.21 ; \mathrm{CI}=1.47-224.78)$, fetal heart rate abnormalities during labor $(\mathrm{OR}=11.74 ; \mathrm{CI}=1.33-103.37)$, augmentation of labor $(\mathrm{OR}=24.04 ; \mathrm{CI}=1.85-311.52)$, second stage of labor lasting more than 30 minutes $(\mathrm{OR}=172.50 ; \mathrm{CI}=20.60-1444.20)$ and tight nuchal cord at birth $(\mathrm{OR}=16.29 ; \mathrm{CI}=2.07-127.87)$.

Conclusions: We recommend the identification of predictive factors for perinatal death in cases of known or suspected nuchal cord in order to consider cesarean section to prevent adverse fetal outcomes.

Keywords: Cameroon, Nuchal cord, Predictive factors, Perinatal death

\section{INTRODUCTION}

Nuchal cord is a common occurrence at delivery and it is known to be associated with birth asphyxia and perinatal death. ${ }^{1-6}$ In Cameroon, the reported incidence of nuchal cord at delivery varies according to different authors from $5.5 \%$ to $16.2 \% .^{6-8}$ Maternal age $<20$ years, first delivery, absence of obstetrical ultrasound during pregnancy; nuchal cord with more than one loop, tight nuchal cord, duration of second stage of labor more than 30 minutes during vaginal delivery have been identified in a previous study as risk factors of birth asphyxia and subsequent newborn death. ${ }^{6}$ However, the perinatal period as a whole was not considered, and a multivariate analysis was not done to identify independent risk factors. The objective of this study was therefore to identify the independent predictive factors for perinatal death in nuchal cord cases.

\section{METHODS}

It was a case-control study carried out from October 1st 2014 to April 30th 2015 in three hospitals of Yaoundé, Cameroon, involving 204 parturients whose babies 
presented with a nuchal cord at delivery. These hospitals were: the Yaoundé Gynaeco-Obstetric and Pediatric Hospital, the Yaoundé Central Hospital and the Cité Verte District Hospital. After the approval of the research protocol by the ethical committee, all parturients with babies presenting with a nuchal cord at delivery, from October 1st 2014 to April 30th 2015, were consecutively recruited. Only deliveries at 28 weeks of pregnancy and above were considered. Each woman was counseled about the study and her consent was obtained prior to recruitment.

A pretested questionnaire was administered by an investigator and information was retrieved from patients' files. The studied variables were: maternal age, parity, gestational age, pregnancy history, ultrasound during pregnancy and its findings, mode of delivery, abnormal findings during labor, duration of expulsion in case of vaginal delivery, induction or augmentation of labor, number of nuchal cord loops, type of nuchal cord (tight or loose), fetal weight, fetal sex, fifth minute Apgar score and perinatal death.
The calculated minimal sample size was 13 cases for 52 controls based on the $6.1 \%$ fetal death rate among deliveries with nuchal cord reported by Nkwabong et al, and using the formula proposed by Schlesselman with a standardized power of $84 \% .^{7,9}$ Statistical analyses were done using Epi info 3.5.4 and SPSS version 20.0 software. The difference was statistically significant for $\mathrm{P}<0.05$. Pearson's Chi square and Fisher's exact test were used to compare proportions. Odds ratio (OR) and its 95\% Confidence Interval (CI) were calculated to assess the association between the variables and perinatal death. Multivariate analysis was performed to identify independent predictive factors.

\section{RESULTS}

Two hundred and four women were recruited during the study period, among which 13 experienced perinatal deaths, giving a rate of $6.4 \%$. Three deaths occurred during the antenatal period $(23.1 \%)$, seven during labor $(53.8 \%)$ and three within the seven-day period following birth $(23.1 \%)$.

Table 1: Significant variables found between the group with perinatal death $(n=13)$ and the group without perinatal death $(n=191)$.

\begin{tabular}{|lllll|}
\hline Variable & $\begin{array}{l}\text { Perinatal death } \\
\mathrm{n}(\%)\end{array}$ & $\begin{array}{l}\text { No perinatal death } \\
\mathrm{n}(\%)\end{array}$ & $\begin{array}{l}\text { Odds ratio } \\
(95 \% \text { CI*) }\end{array}$ & P \\
\hline Primary level of education & $6(46.2)$ & $27(14.1)$ & $5.2(1.62-16.67)$ & 0.01 \\
\hline Referred patient & $7(53.8)$ & $23(12.0)$ & $8.5(2.63-27.57)$ & 0.00 \\
\hline Premature birth & $4(30.8)$ & $18(9.4)$ & $4.2(1.19-15.27)$ & 0.04 \\
\hline Post-term & $2(15.4)$ & $3(1.6)$ & $11.4(1.72-75.39)$ & 0.00 \\
\hline Number of antenatal visits <4 & $7(53.8)$ & $27(14.1)$ & $7.1(2.21-22.69)$ & 0.00 \\
\hline No obstetrical ultrasound done & $6(46.2)$ & $10(5.2)$ & $15.5(4.39-54.84)$ & 0.00 \\
\hline Low weight for date on ultrasound & $2(28.6)$ & $1(0.6)$ & $72.0(5.56-931.09)$ & 0.00 \\
\hline Oligohydramnios on ultrasound & $2(28.6)$ & $4(2.2)$ & $17.7(2.60-120.25)$ & 0.01 \\
\hline $\begin{array}{l}\text { Abnormal fetal heart rate on } \\
\text { ultrasound }\end{array}$ & $2(28.6)$ & $4(2.2)$ & $17.7(2.60-120.25)$ & 0.01 \\
\hline Hypertension during pregnancy & $2(15.4)$ & $4(2.1)$ & $8.5(1.40-51.57)$ & 0.04 \\
\hline Antepartum hemorrhage & $3(23.1)$ & $6(3.1)$ & $9.2(2.01-42.50)$ & 0.01 \\
\hline Induction of labor & $7(53.8)$ & $19(9.9)$ & $10.5(3.21-34.68)$ & 0.00 \\
\hline Augmentation of labor & $10(76.9)$ & $31(16.2)$ & $17.2(4.47-66.12)$ & 0.00 \\
\hline $\begin{array}{l}\text { Fetal heart rate abnormalities during } \\
\text { labor }\end{array}$ & $9(69.2)$ & $18(9.4)$ & $21.6(6.05-77.30)$ & 0.00 \\
\hline Second stage of labor lasting $>30 \mathrm{mn}$ & $6(75)$ & $2(1.7)$ & $172.5(20.6-1444.2)$ & 0.00 \\
\hline Blood-stained amniotic fluid & $2(15.4)$ & $1(0.5)$ & $34.5(2.90-410.97)$ & 0.01 \\
\hline Tight nuchal cord & $12(92.3)$ & $81(42.4)$ & $16.3(2.07-127.87)$ & 0.00 \\
\hline
\end{tabular}

*CI= Confidence Interval.

A comparison of the variables between the group with perinatal deaths (case group) and the one with no perinatal death (control group) found the following significant variables at bivariate analysis (Table 1): primary level of education $(\mathrm{OR}=5.2 ; \mathrm{CI}=1.62-16.67)$, referral from another health facility $(\mathrm{OR}=8.5$; $\mathrm{CI}=2.63$ 27.57), premature birth $(\mathrm{OR}=4.2$; $\mathrm{CI}=1.19-15.27)$, postterm $(\mathrm{OR}=11.4 ; \mathrm{CI}=1.72-75.39)$, number of antenatal visits $<4$ ( $\mathrm{OR}=7.1 ; \mathrm{CI}=2.21-22.69)$, absence of obstetrical ultrasound $(\mathrm{OR}=15.5 ; \mathrm{CI}=4.39-54.84)$, low weight for date on ultrasound $(\mathrm{OR}=72.0 ; \quad \mathrm{CI}=5.56-931.09)$, oligohydramnios on ultrasound $(\mathrm{OR}=17.7 ; \mathrm{CI}=2.60$ 120.25), abnormal fetal heart rate on ultrasound $(\mathrm{OR}=17.7 ; \quad \mathrm{CI}=2.60-120.25)$, hypertension during pregnancy $\quad(\mathrm{OR}=8.5 ; \quad \mathrm{CI}=1.40-51.57), \quad$ antepartum hemorrhage $(\mathrm{OR}=9.2 ; \mathrm{CI}=2.01-42.50)$, induction of labor 
$(\mathrm{OR}=10.5 ; \quad \mathrm{CI}=3.21-34.68), \quad$ augmentation of labor $(\mathrm{OR}=17.2 ; \mathrm{CI}=4.47-66.12)$, fetal heart rate abnormalities during labor $(\mathrm{OR}=21.6 ; \mathrm{CI}=6.05-77.30)$, second stage of labor lasting more than 30 minutes $(\mathrm{OR}=172.5$; $\mathrm{CI}=20.6$ 1444.2), blood-stained amniotic fluid in labor $(\mathrm{OR}=34.5$; $\mathrm{CI}=2.90-410.97)$, and tight nuchal cord at birth $(\mathrm{OR}=16.3 ; \mathrm{CI}=2.07-127.87)$.
Independent predictive factors of perinatal death after multivariate analysis were: post-term $(\mathrm{OR}=209.70$; $\mathrm{CI}=$ 3.09-14212.66), antepartum hemorrhage $(\mathrm{OR}=18.21$; $\mathrm{CI}=1.47-224.78)$, fetal heart rate abnormalities during labor $(\mathrm{OR}=11.74 ; \mathrm{CI}=1.33-103.37)$, augmentation of labor $(\mathrm{OR}=24.04$; $\mathrm{CI}=1.85-311.52)$, second stage of labor lasting more than 30 minutes $(\mathrm{OR}=172.50$; $\mathrm{CI}=20.60$ 1444.20) and tight nuchal cord at birth $(\mathrm{OR}=16.29$; $\mathrm{CI}=2.07-127.87)$.

Table 2: Independent significant variables found after multivariate analysis.

\begin{tabular}{|llll|}
\hline Variable & Adjusted odds ratio & $95 \%$ Confidence interval & P \\
\hline Primary level of education & 4.99 & $0.38-65.48$ & 0.22 \\
\hline Referred patient & 3.34 & $0.29-37.62$ & 0.33 \\
\hline Premature birth & 3.26 & $0.19-55.97$ & 0.41 \\
\hline Post-term & 209.70 & $3.09-14212.66$ & 0.01 \\
\hline Number of antenatal visits $<4$ & 6.43 & $0.60-68.75$ & 0.12 \\
\hline No obstetrical ultrasound done & 1.75 & $0.08-37.43$ & 0.72 \\
\hline Oligohydramnios on ultrasound & 2.78 & $0.07-104.52$ & 0.57 \\
\hline Low weight for date on ultrasound & 22.52 & $0.84-603.46$ & 0.06 \\
\hline Abnormal fetal heart rate on ultrasound & 2.78 & $0.07-104.52$ & 0.06 \\
\hline Hypertension during pregnancy & 15.37 & $0.08-2911.56$ & 0.30 \\
\hline Antepartum hemorrhage & 18.21 & $1.47-224.78$ & 0.02 \\
\hline Induction of labor & 3.54 & $0.27-46.23$ & 0.33 \\
\hline Augmentation of labor & 24.04 & $1.85-311.52$ & 0.01 \\
\hline Fetal heart rate abnormalities during labor & 11.74 & $1.33-103.37$ & 0.02 \\
\hline Second stage of labor lasting $>30 m n$ & 172.50 & $20.60-1444.20$ & 0.00 \\
\hline Blood-stained amniotic fluid & 13.62 & $0.64-287.58$ & 0.09 \\
\hline Tight nuchal cord & 16.29 & $2.07-127.87$ & 0.00 \\
\hline
\end{tabular}

\section{DISCUSSION}

This study identified post-term as an independent predictive factor for perinatal death in nuchal cord cases. The presence of a nuchal cord in a post-term pregnancy is a commonly reported factor for perinatal death as it increases the risk of acute fetal distress. ${ }^{10}$

The occurrence of antepartum hemorrhage is also significantly associated with perinatal death in the presence of nuchal cord. This is not a surprising finding, as antepartum hemorrhage is a widely known risk factor for stillbirth or perinatal death. ${ }^{11-13}$ Therefore its association with nuchal cord might increase this risk.

In this study, the augmentation of labor with oxytocin infusion is found to be a predictive factor for perinatal death when nuchal cord is witnessed at birth. Even though a similar finding has not been reported in the available literature, oxytocin infusion is a welldocumented risk factor for birth asphyxia and perinatal death. ${ }^{14,15}$ The decision to augment labor in the presence of nuchal cord therefore increases the risk of birth asphyxia and subsequent fetal death.
Abnormal fetal heart rate during labor is another predictive factor for perinatal death identified in this series of nuchal cord cases. It has been found by Sandjong et al. to multiply by five the risk of fetal death in Cameroon. ${ }^{16}$ Considering the fact that abnormal fetal heart rate during labor is a common sign of fetal distress, and probable death, this was an expected finding.

The duration of second stage of labor for more than 30 minutes was also found to be a predictive factor for perinatal death. A longer second stage of labor has been reported in nuchal cord cases, especially in nulliparous parturients and multiple looping nuchal cords. ${ }^{3,17}$ This factor has already been reported as a predisposition to birth asphyxia and neonatal death. ${ }^{6}$

In this study, tight nuchal cord was a very significant predictive factor for perinatal death. It is the most common factor associated with adverse neonatal outcomes in nuchal cord cases. $1,6,8,17$

However, study results must be considered with some limitations. The number of subjects included in the case group was limited, just equal to the calculated minimal 
sample size. This might have given some bias to our results.

\section{CONCLUSION}

Post-term, antepartum hemorrhage, fetal heart rate abnormalities during labor, augmentation of labor, second stage of labor lasting more than 30 minutes and tight nuchal cord at birth are independent predictive factors of perinatal death.

Study recommend the identification of predictive factors for perinatal death in a case of known or suspected nuchal cord, in order to consider cesarean section to prevent adverse fetal outcomes.

\section{ACKNOWLEDGEMENTS}

We acknowledge the authorities of Yaoundé GynecoObstetric and Pediatric Hospital, University Teaching Center and the Cité Verte District Hospital, who gave us the permission to carry out the study in their institutions.

Funding: No funding sources Conflict of interest: None declared

Ethical approval: The study was approved by the Institutional Ethics Committee

\section{REFERENCES}

1. Dhar KK, Ray SN, Dhall GI. Significance of nuchal cord. J Indian Med Assoc. 1995;93(12):451-3.

2. Schäffer L, Burkhardt $\mathrm{T}$, Zimmermann $\mathrm{R}$, Kurmanavicius J. Nuchal cords in term and postterm deliveries do we need to know? Obstet Gynecol. 2005;106(1):23-8.

3. Larson JD, Rayburn WF, Crosby S, Thurnau GR. Multiple nuchal cord entanglements and intrapartum complications. Am J Obstet Gynecol. 1995;173(4):1228-31.

4. Assimakopoulos E, Zafrakas M, Garmiris P, Goulis DG, Athanasiadis AP, Dragoumis K, et al. Nuchal cord detected by ultrasound at term is associated with mode of delivery and perinatal outcome. Eur J Obstet Gynecol Reprod Biol. 2005;123(2):188-92.

5. Rhoades DA, Latza U, Mueller BA. Risk factors and outcomes associated with nuchal cord. A populationbased study. J Reprod Med. 1999;44(1):39-45.

6. Foumane P, Nkomom G, Mboudou ET, Dohbit JS, Nguefack S, Moifo B. Risk factors of clinical birth asphyxia and subsequent newborn death following nuchal cord in a low-resource setting. Open J Obstet Gynecol. 2013;3(9):642-7.
7. Nkwabong E, Fomulu JN. Neonatal outcome in cases of nuchal cord in Cameroon. Int J Gynaecol Obstet. 2011;114(3):287-8.

8. Kemfang Ngowa JD, Kasia JM, Nsangou I, Zedjom C, Domkam I, Morfaw F, et al. Nuchal cord and perinatal outcome at the Yaounde General Hospital, Cameoon. Clin Mother Child Health. 2011;8: Article Id C101201.

9. Schlesselman J. Sample size requirements in casecontrol studies of disease. Am J Epidemiol. 1974;99(6):381-4.

10. De Los Santos-Garate AM, Villa-Guillen M, Villanueva-García D, Vallejos-Ruíz ML, MurguíaPeniche MT. NEOSANO's network. Perinatal morbidity and mortality in late-term and post-term pregnancy. NEOSANO perinatal network's experience in Mexico. J Perinatol. 2011;31(12):78993.

11. Bhandari S, Raja EA, Shetty A, Bhattacharya S. Maternal and perinatal consequences of antepartum haemorrhage of unknown origin. $\mathrm{Br} \mathrm{J}$ Obstet Gynecol. 2014;121(1):44-50.

12. Bayou G, Berhan Y. Perinatal mortality and associated risk factors: a case control study. Ethiop J Health Sci. 2012;22(3):153-62.

13. Ntambue AM, Donnen P, Dramaix-Wilmet M, Malonga FK. Risk factors for perinatal mortality in the city of Lubumbashi, Democratic Republic of Congo. Rev Epidemiol Sante Publique. 2012;60(3):167-76.

14. Milsom I, Ladfors L, Thiringer K, Niklasson A, Odeback A, Thornberg E. Influence of maternal, obstetric and fetal risk factors on the prevalence of birth asphyxia at term in a Swedish urban population. Acta Obstet Gynecol Scand. 2002;81(10):909-17.

15. Mota-Rojas D, Villanueva-García D, VelazquezArmenta EY, Nava-Ocampo AA, RamírezNecoechea R, Alonso-Spilsbury M, et al. Influence of time at which oxytocin is administered during labor on uterine activity and perinatal death in pigs. Biol Res. 2007;40(1):55-63.

16. Sandjong T, Tebeu PM, Mbu R, Mboudou ET, Guegang G, Nkwabong E, et al. Intrapartum fetal death in cameroun: an assessment in two referral hospitals in Yaounde, Cameroon. Clin Mother Child Health. 2009;6(2):1123-7.

17. Ogueh O, Al-Tarkait A, Vallerand D, Rouah F, Morin L, Benjamin A, et al. Obstetrical factors related to nuchal cord. Acta Obstet Gynecol Scand. 2006;85(7):810-4.

Cite this article as: Foumane $\mathrm{P}$, Nguefack $\mathrm{S}$, Fouedjio JH, Assam AB, Dohbit JS, Mboudou ET. Predictive factors for perinatal death in nuchal cord cases: a case control study. Int J Reprod Contracept Obstet Gynecol 2016;5:4206-9. 